\title{
MIIASE E PERFURAÇÃO DO RUMEN DE BEZERROS POR LARVAS DE COCHLIOMYIA HOMINIVORAX (Coquerel, 1858). SIGNIFICAÇÃO ECONÔMICA
}

\author{
(MYIASIS AND PERFORATION OF THE RUMEN OF CALVES BY LARVAE \\ OF COCHLIOMYIA HOMINIVORAX (Coquerel, 1858). ECONOMIC \\ SIGNIFICANCE).
}

\author{
U. F. Rocra \\ Z. VAZ \\ Assistente \\ 2 estampas ( 4 figuras)
}

Desde que Cushing \& Patron (1933) demonstraram, em miíases cutâneas de bovinos, que o agente causal não é a Cochliomyia macellaria (Fabricius), como até então se admitia, e sim uma outra espécie, que consideraram como nova e descreveram sob o nome de C. americana, êsse assunto passou a despertar grande interêsse, particularmente entre os investigadores americanos.

No ano seguinte ao do aparecimento dêsse trabalho surgiu a publicação de Aubertin \& Buxton (1934), mostrando que a espécie descrita sob o nome de C. americana é idêntica à que CoQuerel descreveu em 1858, como causadora de miíase nasal num homem de Caiena (Guiana francesa) e denominou Lucilia ho. minivorax. $O$ mesmo entomologista francês publicou em outro trabalho, que veio à luz em 1859, a descrição da larva dêsse parasita, o que facilitou sobremaneira o estahelecimento, feito por AUbertin \& Buxton, da sinonimia de $C$. americana e L. hominivorax.

Z. VAZ (1935) verificou, no Estado de São Paulo, que miíases cutâneas de porcos, cães e bovinos são produzidas por $C$. hominivorax, obtendo-se os adultos por cultura de larvas retiradas de bicheiras dêsses animais. Nesse trabalho, o A. mostrou a possibilidade de se distinguir a $C$. macellaria de $C$. hominivorax pelo exarne da frontália dos machos, sem necessidade, portanto, de se recorrer ao exame da genitália.

* Trabalho realizado em parte no Serviço Veterinário do Condomínio Almeida Prado, em Araçatuba, a cuja direção, na pessoa do Dr. Vicente de Paula de Almeida Prado, deixamos consignados os nossos agradecimentos. 
No mesmo ano, VAZ observou um caso de miíase furunculosa do couro cabeludo de um paciente da Santa Casa de São Paulo por C. hominivorax, que vem referido em trabalho de Franco do Amaral (1940).

Vaz \& Teixeira de Carvalho (1938) descreveram a incidência de uma forma de mirase freqüente da cavidade gengivo-alveolar dos incisivos de bezerrns em período de lactação e verificaram que o agente causal é também, sistemàticamente, a $C$. hominivorax.

Mazza et al. (1939) relataram diversos casos humanos de milases por $C$. hominivorax e SAmuel Pessôa refere (1946), que teve ocasião de observar casos de míases, produzidos pela mesma espécie, em doentes de leishmaniose inclusive com localização naso-faringiana.

Franco do Amaral (1940), descreveu, no homem, dois casos de míases por larvas de $C$. hominivorax - um com localização na face inferior da língua e outro na goteira faringo-laringéia esquerda - e confirmou a possibilidade de se distinguirem os machos de $C$. macellaria e de $C$. hominivorax pelo aspecto da frontália.

Trabalho interessante é o de Melvin (1935), demonstrando experimentalmente, em coelhos e cobaias, a capacidade das larvas de $C$. hominivorax de atravessarem a pele sã.

Já resulta nítida, dos trabalhos acima citados, a importância das larvas de C. hominivorax, como agente causal de doença, quer no homem, como nos animais domésticos. Do ponto de vista econômico, não é possível subestimar essa mosca, pois, como ninguém ignora, as bicheiras, principalmente do gado bovino, incidem entre nós em escala elevada e constituem fator não desprezível de de. preciação do couro dêsses animais.

Incidência também extremamente alta é a da miliase do umbigo de bezerros recém-nascidos e em todos os casos a identificação demonstra sempre que se trata de larvas de $C$. hominivorax. Ora, às bicheiras do umbigo de bezerros atribui-se geralmente um papel importante, como porta de entrarla de bactérias causadoras das septicemias dos recém-nascidos.

A instalação de miíases por larvas de $C$. hominivorax nas lesões de rasco de bovinos, conseqüentes à febre aftosa, complica bastante o quadro clínico dessa virose, prolongando-lhe os efeitos e retardando a recuperação do estado hígido, pela dificuldade de locomoção dos animais atacados e conseqüente incapacidade de procura de alimento.

De tudo o que acima foi dito resulta bem claro que, até o presente momento, a larva de $C$. hominivorax vem sendo referida pela sua incidência em lesões 
ou soluções de continuidade da pele ou ainda em abertura de cavidades naturais, onde destroi tecidos vivos.

Não conhecemos da literatura qualquer referência a localização gastro-intestinal das larvas da $C$. hominivorax. Os poucos casos de miíases gastro-intestinais até agora descritos referem-se à presença de larvas de espécies dos gêneros Calliphora, Fannia e Sarcophaga.

Durante os anos em que trabalhou na direção dos Serviços Veterinários do Condomínio Almeida Prado, em Araçatuba, um de nós (U. F. Rocis), realizando necroscopias, sempre que possivel sistemàticamente, dos bezerros mortos nas Fazendas daquele Condomínio, verificou a perfuração do rumen por larvas de moscas, como causa freqüente de morte.

As Fazendas Almeida Prado, em Araçatuba, pertencentes ao mencionado Condomínio e com extensão aproximada de quatro mil alqueires (10.000 hectares), em pastos de capim Colonião (Panicum máximum, Jacq.), são dedicadas à criação de gado hovino e têm, aproximadamente, de doze a quinze mil vacas de forte mestiçagem 'Zebú, nascendo cêrca de dez mil bezerros por ano.

Trata-se de uma emprêsa admiràvelmente bem organizada, seguramente modelar em nosso meio, que mantém serviço veterinário próprio, incluindo laboratório com, pràticamente, todos os recursos desejáveis não só para a rotina, como também para trabalhos de pesquisa e ao qual se destina uma verba substancial.

Deve-se, por certo, à perfeita organização e à excelente administração a baixa wortalidade de bezerros verificada nessas Fazendas e que oscila em tôrno de 10\%, porcentagem sem dúvida excepcional, se se consideram o número de nascimentos e o regime extensivo da criação.

Pois bem, dêsses bezerros mortos por várias causas, das quais sobrelevam tôdas as chamadas septicemias dos recém-nascidos, $8 \%$ no inverno a $15 \%$ no verão são vitimados por perfuração do rumen por larvas da $C$. hominivorax, variação que se explica por circunstâncias dependentes das condições climáticas estacionais que influem no ciclo evolutivo das moscas e no coeficiente mensa" de nascimento de bezerros.

A incidência da perfuração do rumen e conseqüente peritonite se dá principalmente em bezerros dentro do primeiro mês de vida, mas ocorre lambém, mênos freqüentemente, em bezerros até o segundo mês, como se pôde observar em mais de 300 necroscopias realizadas.

\section{LESOES OBSERVADAS NO RUMEN}

O exame do rumen dos bezerros vitimados por êsse tipo de miiase mostrava a presença de larvas de mosca, quase sempre em fase avançada da evolução e 
localizando-se na parte mais dorsal do órgão, isto é, no assim chamado átrio do rumen.

Queremos ressaltar a constância da localização das larvas nesse ponto, que é também aquêle pelo qual se dá a perfuração. Em alguns casos a lesão é inicial e discreta, como se fôra uma simples erosão da mucosa, sem reação de qualquer natureza, como se pode ver na fotografia 1 .

Em lesōes mais antigas notava-se uma ou mais zonas de perfuração, próximas umas às outras, com evidente reação tissular e, do lado do peritônio, formação de aderências reacionais (fotografias 2 a 4 ). Não era infrequiente o encontro de larvas na cavidade abdominal.

O número de larvas encontradas variava bastante, por via de regra em tôno de 5 ou 6 exemplares. Casos houve, porém, de se encontrar apenas uma larva, um outro com 225, além de outro em que foi encontrada apenas a lesão, sem as larvas, que teriam provàvelmente sido eliminadas ou caído na cavidade poritonial.

\section{ORIGEM DA LESÃO}

Ocorre indagar como as larvas da $C$. hominivorax conseguiram atingir o ri1men, isto é, se se trata de larvas que se instalaram primitivamente nesse órgão, ou se são larvas deglutidas pelos bezerros, retiradas ou provenientes de lesóes cutâneas, umbelicais ou ainda de míase alvéolo-gengival.

E' fato incontestável que as larvas da $C$. hominivorax necessitam de suprimento de oxigênio e que, por outro lado, tratando-se de tipo de larvas das chamadas biontófagas, isto é, que se nutrem de tecidos vivos, parece pouco provável que o rumen tenha sido o ponto inicial de localização delas, por isso que, sendo dotadas de grande voracidade, promoveriam a perfuração desde o início, sem que houvesse tcmpo para que atingissem o estado avançado da evolução em que freqüentemente são encontradas. Basta dizer que muitas vêzes conseguimos obter adultos a partir de larvas colhidas no rumen e que puparam ràpidamente.

Por outro lado, devemos assinalar que em todos os casos de miíases do rumen encontrávamos míase externa, quase sempre umbelical, ou lesōes de miiases sem larva e ainda míase alvéolo-gengival em quase todos os casos.

E:sas considerações nos levam a admitir como mais provável a hipútese de que se trata de larvas arrastadas mecânicamente por lambimento de lesões de miíases externas e que, portanto, a sua presença no rumen constitui localização secundlária.

E' sabido quc o bezerro no primeiro mês de vida alimenta-se quase que exclusivamente de leite e que êste alimento não faz estágio no rumen, passando 
diretamente do esôfago para o abomaso, através da goteira esofagiana. Por isso o rumen não é funcional nessa fase e a mucosa que o reveste é delicada e ainda pouco corneificada.

Substâncias sólidas ingeridas nessa fase estagiam no rumen e êsse seria o destino das larvas deglutidas. Sendo elas carnivoras, atacariam com facilidade a delicada mucosa do rumen e, posteriormente, as camadas subjacentes, dai resultando a perfuração do órgão.

A localização, na parte mais dorsal do átrio do rumen, explicar-se-ia, a nosso ver, pelo fato de ser o oxigênio provàvelmente mais abundante nessa região.

A importância econômica dêsse tipo de parasitose encontra exemplo nas Fazendas Almeida Prado, onde mais de uma centena de bezerros morre por ano em conseqüência dela.

\section{RESUMO E CONCLUSOES}

Os AA. descrevem um novo tipo de míase produzido por larvas de $C$. hominivorax (Coquerel, 1858). Sin. C. americana (Cushing \& Patton, 1933), em bezerros até o segundo mês de vida, com localização no átrio do rumen.

As larvas, provàvelmente arrastadas por lambimento de lesões de miíases externas e deglutidas pelo bezerro, instalam-se no átrio do rumen, perfuram a mucosa e camadas subjacentes, irrompendo na cavidade abdominal e provocando peritonite.

Mais de 300 necroscopias, realizadas durante o ano, mostraram que a percentual de mortes de bezerros atribuíveis à míase do rumen, nas Fazendas do Condomínio Almeida Prado, em Araçatuba, oscilou entre 8\% no inverno e 15\% no verão, sôbre o total de óbitos.

A importância econômica dêsse tipo de míase fica patente pelo fato de, sòmente nas Fazendas Almeida Prado, mais de cem bezerros serem vitimados anualmente por ela.

\section{SUMMARY AND CONCLUSIONS}

The authors describe a new type of myiasis which occurs in calves from one to two months old, caused by the larvae of the "screw-worm fly" - Cochliomyia hominivorax (Coquerel, 1858), Sin. C. americana (Cushing and Patton, 1933) - with localization in the rumen.

The larvae, probably removed from external myiasis by the common calf's habit of licking wounds are swallowed and set themselves up in the atrium of the rumen, there piercing the mucosa and subjacent layers, causing peritonitis and of ten invading the abdominal cavity. 
From some hundreds of post-mortem examinations made with the intention of establishing the various causes of death of calves in the "Fazendas Almeida Prado", belonging to the "Condominio Almeida Prado", Araçatuba, it was found that myiasis of the rumen accounted for eight (winter) to fifteen (summer) percent of the total, this variation probably due mainly to seasonal circumstances.

The economic significance of this type of myiasis is emphasized by the fact that, in these "Fazendas" more than 100 calves are dying yearly from perforation of the rumen.

On the other hand, this paper points out the possibility of the internal localization of the larvae of $C$. hominivorax.

\section{BIBLIOGRAFIA}

Amarar., A. F. D. - 1940 - Ohservações em tôrno de 2 casos de míase humana pela "Cochliomyia hominivorax" (Coq., 1858). Acta Médica, R. Janeiro, 5(3):134

Aunertin, D. \& Buxton, P. A. - 1934 - "Cochliomyia" and myiasis in tropical Amierica. Ann. Trop. Med. \& Parasitol., 28:245-54

Coquerei - 1858 - Note sur des larves appartenant a une nouvelle espece de Diptere. Ann. Soc. Entom. France, 27:171

Coquerer. - 1858 - Des larves de dipteres developpées dans le sinus frontaux ct les fosses nasales de l'homme. Ann. Cen. de Med. Ser., 11:513

Coquerer, - 1859 - Description de la larve de "Iucilia hominivorax". Ann. Soc. Entom. France, $28: 236$

Cushring, E. C. \& Patron, W. S. - 1933 - Studies on the higher Diptera of medical and veterinary importance. "Cochliomyia americana" sp. nov., the screw worm of the New World. Ann. Trop. Med. \& Parasitol., 27:539-51

Mazza, Si. et al. - 1939 - Investigaciones sobre Dipteros argentinos. I: Miasis. Misión Estudios Pat. Reg. Argentina (Jujuy). Publicacion n* 4.1.

Meture - 1935 -- in Mazaa et al., op. cit.

Prssôa, S. 13. - 1946 - Parasitologia médica. S. Paulo, Editora Renascença S/A.

Vaz, \%. - 1935 - "Cochliomyia hominivorax" agente causal de myiases em animaes domistiecis do Mrasil (Caricteres que permitem distinguí-la de "C. macellaria"). Rez". Biol. Hyg., S. I'aulo, 6(1):1:3-8

Vaz, \%. \& Thixeira ne Carvaino, G. - 1938 - Sôhre um tipo interessante de míasc dos bezerros e scu agente causil. Rer. Fac. Mod. Vet., S. Paulo, 1(1):483-8 


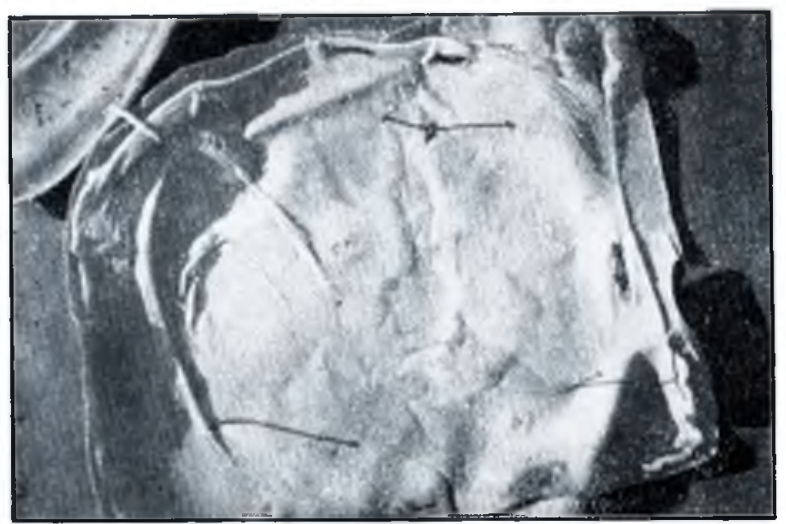

lolografia l Idesĩo inicial da mocosil do rumen por larvas de ('. hominivorax. Frosito, senn perfuracite.

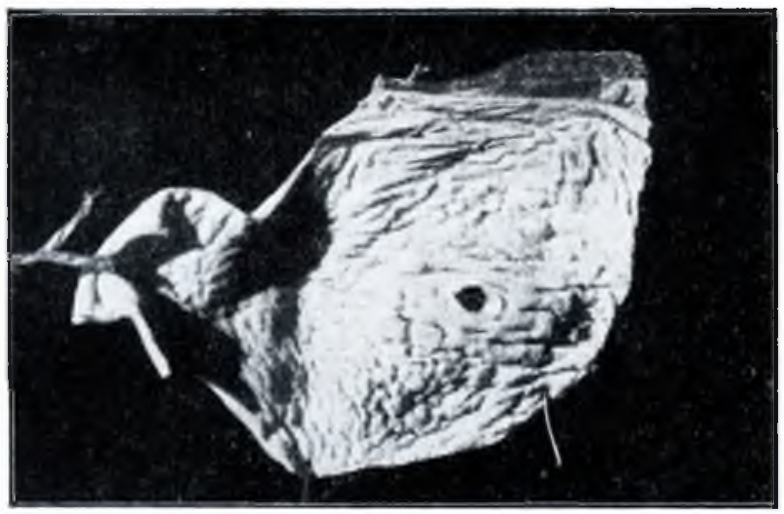

loblografia 2 - P'erfurição da patrede do rumen por larvas de C. hominicorax. I cesão ínica. 


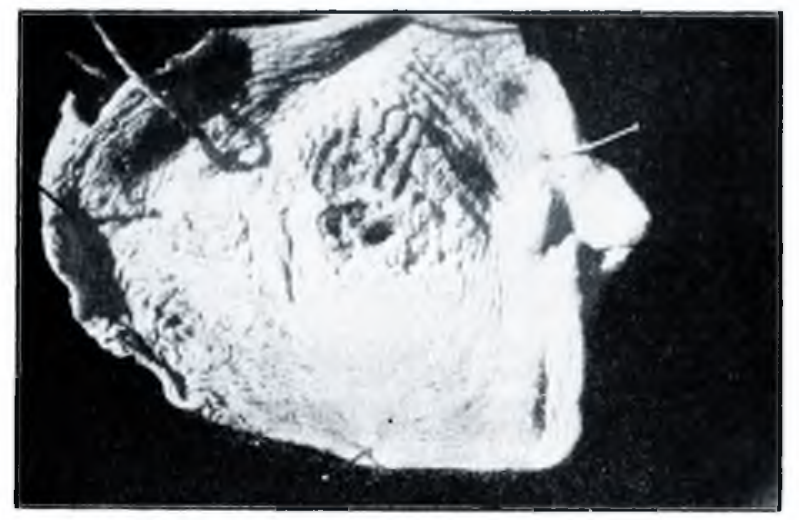

Fotografia 3 - Várias perfurações da parede do rumen por larvas de $C$. hominivosued. Aspecto da face internit.

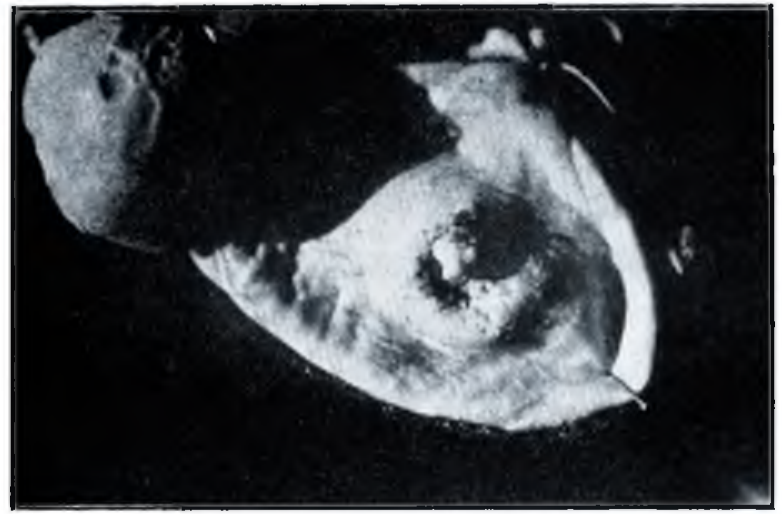

Fotografia 4 - Rumen perfurado por larvas de hominicorex visto pela face peritoneat. 